\title{
The Effects of Pomegranate (Punica granatum L.) Peel Methanolic Extract on Methotrexate Induced Changes in Hepatic Antioxidant Enzymes of Rats
}

\author{
Neda Ghamarzad Shishavan, ${ }^{1}$ Mehran Mesgari Abbasi, ${ }^{2,}{ }^{*}$ Rogayeh Amini Afshar, ${ }^{3}$ Parvin Zakeri \\ Milani, ${ }^{4}$ and Fariba Yahyavi ${ }^{5}$ \\ ${ }^{1}$ Digestive Diseases Research Center, Shariati Hospital, Tehran University of Medical Sciences, Tehran, IR Iran \\ ${ }^{2}$ Drug Applied Research Center, Student Research Committee, Tabriz University of Medical Sciences, Tabriz, IR Iran \\ ${ }^{3}$ Faculty of Science, Urmia University, Urmia, IR Iran \\ ${ }^{4}$ Liver and Gastrointestinal Research Center, Tabriz University of Medical Sciences, Tabriz, IR Iran \\ ${ }^{5}$ Department of Basic Science, School of Veterinary Medicine, Ferdowsi University of Mashhad, Mashhad, IR Iran \\ "Corresponding author: Mehran Mesgari Abbasi, Drug Applied Research Center, Student Research Committee, Tabriz University of Medical Sciences, Tabriz, IR Iran. Tel: \\ +98-9141168681, Fax: +98-4133372653, E-mail: mesgarim@tbzmed.ac.ir
}

Received 2016 July 02; Revised 2016 April 03; Accepted 2016 April 12.

\begin{abstract}
Background: Methotrexate (MTX), as one of the most pivotal drugs in treatment of some malignancies and autoimmune diseases, is associated with damages to different tissues particularly the liver tissue through impairing the balance between antioxidant and pro-oxidants. Pomegranate peel is a great source of polyphenols with antioxidant function that has recently become a center of attention.

Objectives: The current study was undertaken to investigate the effects of MTX and pomegranate peel methanolic extract (PPME), alone and in combination, on liver antioxidants of rats.

Methods: Antioxidant capacity, total phenolic and flavonoid contents of PPME were analyzed. 32 rats were divided into (1) control, (2) orally received $500 \mathrm{mg} / \mathrm{kg}$ PPME, (3) intramuscularly received $10 \mathrm{mg} / \mathrm{kg}$ MTX, and (4) PPME (for 18 days) and MTX (for 3 days beginning from the 10th day) groups. After the experimental period, the rats were euthanatized and tissue samples were obtained for antioxidant analysis.

Results: PPME had a considerable antioxidant capacity, as well as total phenolic and flavonoid contents. There were low liver contents of Glutathione peroxidase (GPx) and Catalase and a high level of Malondialdehyde and Superoxide dismutase (SOD) in the Methotrexate group compared to the control group $(\mathrm{P}<0.05)$. In the Methotrexate-PPME group, PPME could increase the GPx and Catalase contents and decrease the SOD content of the liver compared to the Methotrexate group. GPx of liver samples in the PPME group decreased $(\mathrm{P}<0.05)$. GPx decreased and Malondialdehyde increased in the Methotrexate-PPME group compared to the control group $(\mathrm{P}<0.05)$.

Conclusions: Methotrexate can surprisingly increase SOD and Malondialdehyde and decrease Catalase contents. PPME can decrease GPx and relatively prevent the effects of Methotrexate on SOD and Catalase contents of the liver tissue. However, further studies are recommended.
\end{abstract}

Keywords: Liver, Methotrexate, Oxidative Stress, Pomegranate Peel Extract

\section{Background}

Methotrexate (MTX), which has long been used as an effective drug for treatment of numerous diseases such as rheumatoid arthritis, systemic lupus erythematosus, cancer, etc. (1), as many other drugs has some life-threatening adverse effects particularly liver enzyme abnormalities, hepatotoxicity, pneumonitis, and nephrotoxicity, which mostly limit its clinical application (2). Among these unpleasant effects, hepatotoxicity is more closely associated with the long term use of this drug. Although the underling mechanism is not fully understood, MTX causes a reduction in the availability of NADPH in cells and glutathione (GSH) level, which is dependent on NADPH to maintain its reduced state. All these can result in the inhibition of antioxidant defense system and increased oxidative stress $(3,4)$. Therefore, the necessity of antioxidant consumption during MTX treatment appears to be obvious (5).

The therapeutic evaluation of natural products in hepatic disorders has been noticed in last few years (6) and various natural and synthetic products have been tested by researchers to decrease hepatic damages $(7,8)$. Pomegranate (Punica granatum L.) has recently attracted all attention

Copyright (c) 2016, Jundishapur Journal of Natural Pharmaceutical Products. This is an open-access article distributed under the terms of the Creative Commons Attribution-NonCommercial 4.0 International License (http://creativecommons.org/licenses/by-nc/4.0/) which permits copy and redistribute the material just in noncommercial usages, provided the original work is properly cited. 
due to its beneficial and nutraceutical properties in several diseases such as cancer, diabetes mellitus, and cardiovascular diseases (9). This great action of pomegranate is ascribed to a large number of phytochemicals therein including hydrolysable tannins and phenolic compounds found in different parts of this miracle fruit $(9,10)$. The most interesting thing in this regard is the higher amount of these phytochemicals in non-edible fraction especially in the peel of the fruit. Ellagitannins and the pomegranatepeculiar punicalagin are important polyphenols, which function as pivotal anti-inflammatory and antioxidant agents (9). Based on the findings of latest researches on pomegranate peel extract (PPME), it seems that this waste part of the fruit might play a more important and promising role in the control of oxidative stress through radical scavenging activity and chelation of transition metals (9). There are several in-vitro and in-vivo evidence and epidemiological studies confirming antioxidant property of PPME and its efficacy in the control of oxidative stressmediated diseases (11).

Although the use of extracts isolated from pomegranate peels has been recently the center of attention because of their potential function in different pathways, research in this regard is scanty that does not provide information about its efficacy in the improvement of antioxidant enzymes related to specific tissues including liver after methotrexate administration.

\section{Objectives}

The current study was undertaken to investigate the effects of Methotrexate and pomegranate peel methanolic extract (PPME), alone and in combination, on liver antioxidants of rats.

\section{Methods}

\subsection{Extraction}

Pomegranates (Punica granatum L., Post-Ghermez variety, 5-64-WS) (12) were purchased from the Shiraz suburbs (Fars province, Iran). The pomegranates were washed and peeled manually and the peels were separated and air dried in a $40^{\circ} \mathrm{C}$ oven for 24 hours. The peels turned into a coarse powder. After that, the powder (500 g) was mixed with methanol (Merck, Germany) (1:10 w/v). After 96 hours, the mixture was filtered through $0.45 \mu$ pore size filter (13, 14) and the solvent was completely evaporated by a rotary vacuum evaporator (Hidolf, Germany) at $40^{\circ} \mathrm{C}$. The value of extraction efficiency was about $5 \%$ and the pomegranate peel extract (PPME) was stored at $-70^{\circ} \mathrm{C}$ in a freezer until performing the tests.

\subsection{Animals}

32 male Wistar rats, weighing $200 \pm 15 \mathrm{~g}$, were maintained under standard conditions $\left(22 \pm 2^{\circ} \mathrm{C}, 12\right.$ hours light/12 hours dark cycles) during the experiments. A standard diet and clean water were provided for the rats ad libitum.

The proposal and the animal procedure were approved by the Tabriz University of Medical Sciences' research ethics committee (certificate No.: 5-4-11060, 24 Feb 2014) and the study was conducted according to the European commission directive 86/609/EEC for animal experiments.

\subsection{Procedures}

Similar previous animal studies were considered for choosing sample size (15). The rats were randomly divided into 4 groups using the Rand-list software $(\mathrm{n}=8)$. Group I was the placebo control group that orally received normal saline for 18 days. Group II was the pomegranate group that orally received $500 \mathrm{mg} / \mathrm{kg}$ PPME for 18 days. Group III was the MTX group that intramuscularly received $10 \mathrm{mg} / \mathrm{kg}$ MTX for 3 days, beginning from the 10th day. Group IV was a treatment group that orally received $500 \mathrm{mg} / \mathrm{kg}$ PPME for 18 days, and intramuscularly received $10 \mathrm{mg} / \mathrm{kg}$ MTX for 3 days, beginning from the 10th day.

After the intervention, the rats were euthanatized. The liver tissue samples were obtained. $100 \mathrm{mg}$ samples of the tissue were homogenized by a glass tissue homogenizer in $1 \mathrm{~mL}$ ice cold PBS (pH, 7.4). Afterwards, the homogenized samples were centrifuged at $10,000 \mathrm{~g}$ for 10 minutes at $4^{\circ} \mathrm{C}$. The supernatants were removed and placed in $-70^{\circ} \mathrm{C}$ deep freezer until performing the tests.

\subsection{Biochemical Analyses}

Total antioxidant capacity (TAC), glutathione peroxidase (GPx), and superoxide dismutase (SOD) of the supernatants were assayed by Biorex diagnostics commercial kits (UK). Malondialdehyde (MDA) contents of the supernatants were determined using thiobarbituric acid method (16). Catalase enzyme activities of the supernatants were determined by Cayman kit (USA). The protein contents of the supernatants were assessed by Parsazmun kit (Karaj, Iran). All results were normalized by the protein contents of supernatants. An Abbott Alcyon 300 automated biochemistry analyzer (USA) was used for the abovementioned colorimetric assays.

\subsection{PPME Analyses}

The PPME antioxidant capacity was assayed by the DPPH assay method (17). The samples reduction capacities 50 (RC50) were stated as $\mu \mathrm{g} / \mathrm{mL}$. The quercetin RC50, as 
the control material, was $3.9 \mu \mathrm{g} / \mathrm{mL}$. Total phenolic equivalent was assessed by Folin-Ciocalteu reagent, while a Gallic acid standard curve was used. The result reported as mg of Gallic acid equivalent (GAE) per gram of extract (18). Total flavonoids were assayed by spectrophotometric method (19).

\subsection{Statistical Analysis}

SPSS (version 11.5) was used for statistical analyses (SPSS Inc., Chicago, IL, USA). One-way analysis of variance (ANOVA) was used to compare parameters between the groups for normally distributed data. Tukey's post-hoc test was used for multiple comparisons. Furthermore, the results of Levene's test showed the equality of variances of the groups. The results were expressed as mean \pm 1 standard deviation (SD). P values less than 0.05 were considered statistically significant.

\section{Results}

\subsection{The Antioxidant Properties, Polyphenol and Flavonoid Con-} tents of PPME

The composition of the pomegranate peel methanolic extract in terms of poly-phenolic and flavonoid compounds and antioxidant properties is represented in Table 1.

Table 1. Composition of Pomegranate Peel Extract (PPME) (Average of Three Measurements)

\begin{tabular}{lccc}
\hline Sample & $\begin{array}{c}\text { Antioxidant } \\
\text { Activity, RC50; } \\
\mu \mathbf{g} / \mathbf{m L}\end{array}$ & $\begin{array}{c}\text { Total Phenolic } \\
\text { Content, mg } \\
\text { GAE/g Extract }\end{array}$ & $\begin{array}{c}\text { Total } \\
\text { Flavonoid, \% }\end{array}$ \\
\hline $\begin{array}{l}\text { Pomegranate } \\
\text { Peel Extract }\end{array}$ & $15 \pm 0.2$ & $153.2 \pm 0.3$ & $1.04 \pm 0.03$ \\
\hline
\end{tabular}

\subsection{Changes in Antioxidant Enzymes Following MTX and PPME Administrations}

Table 2 displays the status of all parameters measured in this research in the 4 study groups. MDA and surprisingly SOD and TAC liver contents showed a great enhancement while a reduction was observed in the content of liver GPX and CAT in the group of rats receiving MTX compared to the other groups. PPME administration with MTX augmented the levels of GPx and CAT and decreased the contents of MDA, SOD, and TAC compared to the MTX-treated group.

\subsection{Effects on $S O D$}

Treatment of the rats with MTX surprisingly caused a significant increase in the SOD liver content when compared with the group receiving $\operatorname{PPME}(\mathrm{P}=0.01)$. In addition, MTX combined with PPME pre-treatment led to a significant increase in the liver SOD content in comparison with the group receiving PPME alone $(\mathrm{P}=0.039)$ (Figure 1 ).

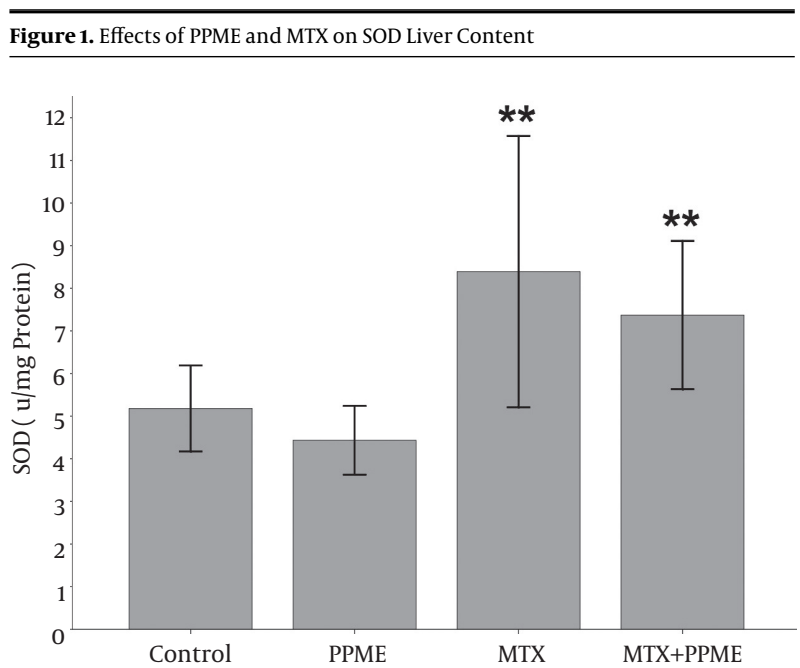

Values are expressed as mean $\pm \mathrm{SD}$; ** Significantly different at $(\mathrm{P}<0.05)$ when compared with PPME-treated rats.

\subsection{Effects on $M D A$}

The content of liver MDA as a product of lipid peroxidation increased significantly following MTX administration when compared with the control $(\mathrm{P}=0.036)$ and PPME receiving groups $(\mathrm{P}=0.008)$.

However, the administration of both PPME and MTX did not alter the MDA level compared to the MTX-treated group (Figure 2 ).

\subsection{Effects on CAT}

The administration of MTX caused a reduction in the content of liver CAT compared to the control group $(\mathrm{P}=$ 0.016). It increased non-significantly following the administration of PPME combined with MTX when compared with the MTX-treated group (Figure 3).

\subsection{Effects on $G P x$}

The PPME administration caused a significant increase in the content of liver GPx when compared to the control group $(\mathrm{P}=0.032)$ and $\mathrm{PPME}$ combined with MTX-pretreated group $(P=0.019)$. However, the low content of liver GPX in the MTX-treated rats compared to the other groups was not significantly different (Figure 4). 
Table 2. Effects of Pomegranate Peel Extract (PPME) on Liver Antioxidant Enzymes in Rats Following Methotrexate Treatment (Average of Three Measurements)

\begin{tabular}{lcccc}
\hline Group & GPX & MDA & CAT & SOD \\
\hline Control & $0.427 \pm 0.037$ & $0.533 \pm 0.028$ & $25.615 \pm 1.397$ & $5.180 \pm 1.007$ \\
PPME & $0.298 \pm 0.058^{\mathrm{b}}$ & $0.528 \pm 0.054$ & $28.516 \pm 8.707$ & $4.434 \pm 0.806$ \\
MTX & $0.260 \pm 0.113$ & $1.698 \pm 0.400^{\mathrm{b}}$ & $18.828 \pm 2.323^{\mathrm{b}}$ & $8.204 \pm 2.315^{\mathrm{c}}$ \\
MTX + PPME & $0.296 \pm 0.052^{\mathrm{b}}$ & $1.735 \pm 0.693^{\mathrm{b}}$ & $26.588 \pm 10.035$ & $0.216 \pm 0.016$ \\
\hline
\end{tabular}

Abbreviations: CAT (nmol/min/mg protein), Catalase; GPx (u/mg protein), Glutathione peroxidase; MDA (nmol/mg protein), Malondialdehyde; SOD (u/mg protein), Superoxide dismutase; TAC (mmol Trolox equivalent/mg protein) total antioxidant capacity.

${ }^{\mathrm{a}}$ Values are expressed as mean $\pm \mathrm{SD}$.

${ }^{\mathrm{b}}$ Significantly different at $(\mathrm{P}<0.05)$ when compared with the control group.

${ }^{\mathrm{C}}$ Significantly different at $(\mathrm{P}<0.05)$ when compared with PPME-treated rats.

Figure 2. Effects of PPME and MTX on MDA Liver Content

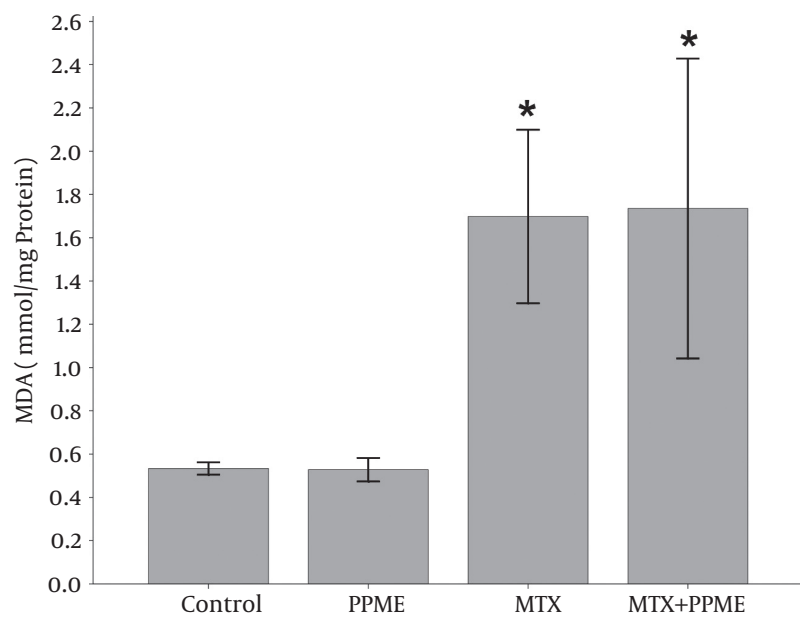

Values are expressed as mean $\pm \mathrm{SD} .{ }^{*}$ Significantly different at $(\mathrm{P}<0.05)$ when compared with the control group.

\subsection{Effects on TAC}

TAC measurements in the 4 groups are represented in Figure 5. TAC depletion ( $0.194 \pm 0.005 \mathrm{nmol} / \mathrm{mg}$ protein) was found in the rats receiving PPME when compared to the other groups, though the difference was not significant. MTX administration augmented TAC level as compared to the other groups $(\mathrm{P}>0.05)$.

\section{Discussion}

Composition of the pomegranate peel methanolic extract was similar to that of the polyphenol extractives in a research conducted by Saad et al. Similarly, on the basis of their findings, phenolic contents of pomegranate peel ranged from 134.3 to $181.0 \mathrm{mg}$ GAE/g DW [mg Gallic acid equivalent (GAE) per g of dry weight (DW)] (20).

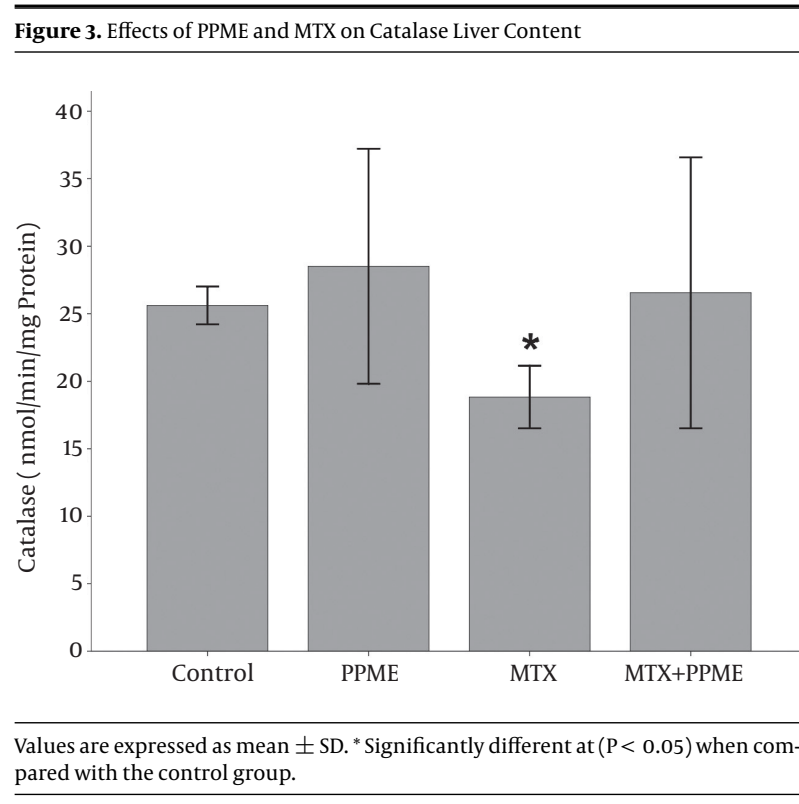

Another study found that water extract from fresh peel contained higher levels of polyphenol contents such as 223 $\pm 3 \mathrm{mg} \mathrm{GAE} / 100 \mathrm{~g}$ fresh peel (8) and 344 - $381 \mathrm{mg} \mathrm{GAE} / 100$ $\mathrm{g}$ fresh peel (21). Given the higher polyphenol contents in unwashed peels, it seems that water-soluble polyphenols might be eliminated by washing (20). Some conflicting data in this regard could be explained by difference in the stage of maturity and the mean annual precipitation or even in the solvents used for extraction (20). Negi et al. found that among methanol, acetone, and water used for the extraction of antioxidants from pomegranate peel, methanol extract represented the maximum antioxidant activity (22). A high extent of pomegranate varieties exists in Iran; the extract composition is affected by the pomegranate genotype diversity, which is classified on the basis of fruit characteristics as morphology, taste, color, size, soluble solids, acidity ratio, time of ripening, and dif- 
Figure 4. Effects of PPME and MTX on GPX Liver Content

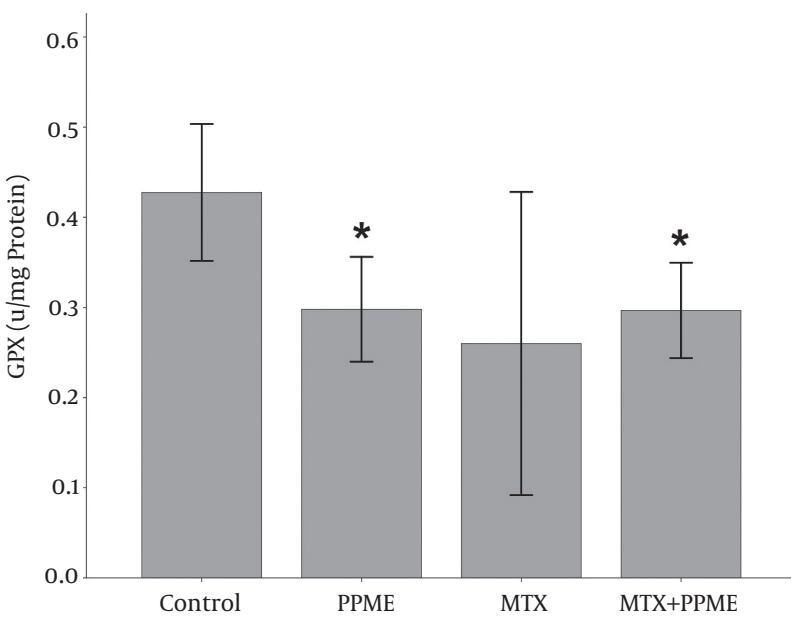

Values are expressed as mean $\pm \mathrm{SD} .{ }^{*}$ Significantly different at $(\mathrm{P}<0.05)$ when compared with the control group.

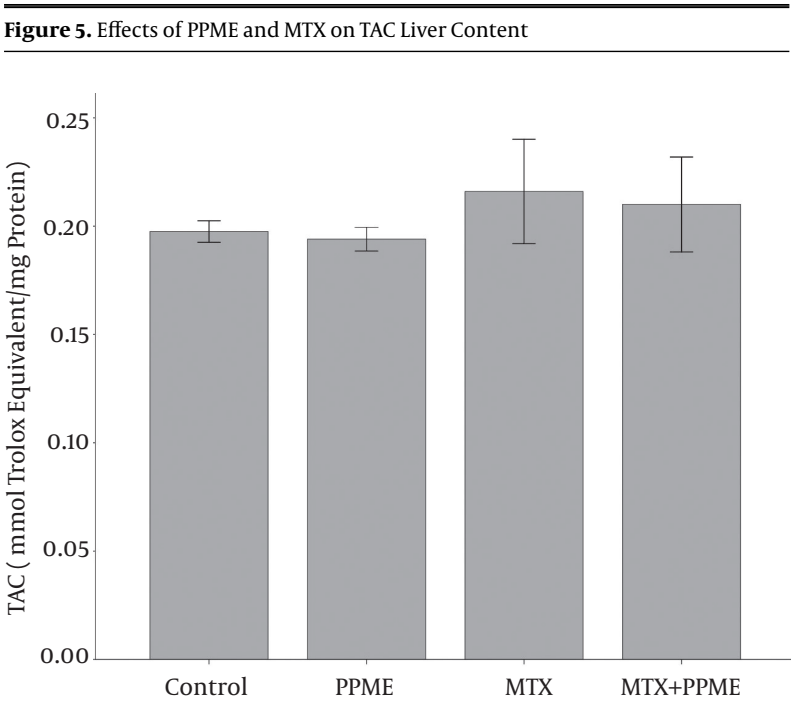

Values are expressed as mean $\pm S D$.

ferent geographical regions (12)

The present study showed an impaired redox status following MTX administration. MTX-treated rats indicated decreased levels of antioxidant enzymes including GPx and CAT. On the other hand, MDA as a byproduct of lipid peroxidation elevated in the rats receiving MTX as compared to the other groups. Additionally, an improved antioxidant system after PPME administration alone or combined with MTX was observed. Despite these effects, no significant differences were observed between the group receiving MTX and the group receiving PPME and MTX combination.
MTX can adversely affect different tissues especially liver, which can be damaged histopathologically and biochemically. It is postulated that most of the MTX metabolisms like converting to its active metabolite, 7hydroxymethotrexate, occur in the liver. Then, it can interact with some cellular pathways to, for example, inhibit oxygen uptake in some cells, reduce the trans-plasma membrane redox activity, and increase glycogenolysis. All these events result in the inhibition of energy production, which can be compensated with some processes in mitochondria generating ROS as byproducts. On the other hand, cellular antioxidant defense system, which is responsible for scavenging activity, is weakened consequently due to the toxicity of MTX (3). In this sense, the inhibition of NADPH-dependent dehydrogenases such as glucose-6-phosphate dehydrogenase, which has been underlined in previous studies (23), makes us think that MTX might be involved in the reduction of NADPH availability in the cells. This event consequently causes an inhibition of glutathione reductase activity, which is dependent on NADPH and eventually the inhibition of GSH cycle (24). Therefore, this conclusion can be drawn that NADPH reduction accounts for the impaired antioxidant system following MTX administration. Our findings were in line with several recent evidence on the unpleasant effects of MTX suggesting the reduction of antioxidant liver content such as GPX and CAT and the increase of MDA level as a pro-oxidant agent (4, 25-27).

Our study has yielded striking results, as well. On the basis of our findings, exposure to MTX caused an increase in TAC as well as SOD levels. The findings of the current study are consistent with those of Oktar and colleagues who found an enhancement in the TAC level of liver in MTXtreated mice. They showed significantly higher levels of total antioxidant capacity (TAC) and total oxidative stress in the liver after methotrexate administration compared to the control group (28). Another unanticipated finding was the higher levels of SOD in the MTX group, which is in agreement with the findings of Najah et al. showing an elevated content of liver SOD in MTX-treated rabbits (29) and another study in which CAT levels markedly increased in the liver of rats after MTX administration (30).

More recently, literature has suggested the protective effects of pomegranate peel extract on food oxidative stability after addition to some food items including dairy products, fish, wheat bread, de-alcoholised red wine, jam, and juice without any unpleasant effect on taste or other aspects of their health properties (9). Additionally, most evidence collected to date has supported its antioxidant feature in different tissues $(8,31-34)$.

The outputs of this study are in line with other researches supporting the effects of pomegranate peel ex- 
tract on antioxidant enzymes in rats' liver $(31,32)$. In our study, PPME administration either alone or in combination with methotrexate caused a great enhancement in the levels of some antioxidant enzymes such as GPx and CAT and a reduction in the MDA level when it was used alone. However, SOD and TAC levels which surprisingly elevated in the MTX group tended to decrease in the PPME receiving group and the MTX receiving combined with PPME pretreatment group, as well. This finding is inconsistent with those showing an enhancement in the plasma level of TAC after the administration of methanol extract of pomegranate peel against oxidative stress induced by treatment with mercuric chloride ( $\mathrm{HgCl} 2)$ in a rat model (33).

The reason for this is not clear; but it may have something to do with the solvent for extraction that can affect the polyphenols content in pomegranate peel or its unknown optimal dose. In addition, the dose of methotrexate used to induce oxidative stress may not be proper to change SOD and TAC liver content. The results would be more reliable if either there was a control group with no injection or the intervention period was longer or different doses of drug and extract were used. However, this is the first study designed to investigate the effects of PPME on liver antioxidant changes induced by methotrexate. The determination of poly-phenolic and flavonoid compounds and antioxidant properties in pomegranate peel methanolic extract was one of the strength of this work.

In conclusion, Methotrexate can significantly increase SOD and MDA and decrease CAT contents and, on the other hand, PPME can significantly decrease GPx and relatively prevent the effects of methotrexate on SOD and CAT contents of the liver tissue of rats.

Due to the controversies between the effects of methotrexate and PPME on different antioxidants as well as in different tissues, it seems that more research needs to be undertaken on this topic.

\section{References}

1. Swaminath A, Taunk R, Lawlor G. Use of methotrexate in inflammatory bowel disease in 2014: A User's Guide. World J Gastrointest Pharmacol Ther. 2014;5(3):113-21. doi: 10.4292/wjgpt.v5.i3.113. [PubMed: 25133040].

2. Hashkes PJ, Becker ML, Cabral DA, Laxer RM, Paller AS, Rabinovich CE, et al. Methotrexate: new uses for an old drug.JPediatr. 2014;164(2):2316. doi:10.1016/j.jpeds.2013.10.029. [PubMed: 24286573].

3. Tabassum H, Parvez S, Pasha ST, Banerjee BD, Raisuddin S. Protective effect of lipoic acid against methotrexate-induced oxidative stress in liver mitochondria. Food Chem Toxicol. 2010;48(7):1973-9. doi: 10.1016/j.fct.2010.04.047. [PubMed: 20451574].

4. Hemeida RA, Mohafez OM. Curcumin attenuates methotraxateinduced hepatic oxidative damage in rats. J Egypt Natl Canc Inst. 2008;20(2):141-8. [PubMed: 20029470].

5. Elango T, Dayalan H, Gnanaraj P, Malligarjunan H, Subramanian S. Impact of methotrexate on oxidative stress and apoptosis markers in psoriatic patients. Clin Exp Med. 2014;14(4):431-7. doi: 10.1007/s10238013-0252-7. [PubMed: 23949337].

6. Forouzandeh H, Azemi ME, Rashidi I, Goudarzi M, Kalantari H. Study of the Protective Effect of Teucrium polium L. Extract on Acetaminophen-Induced Hepatotoxicity in Mice. Iran J Pharm Res. 2013;12(1):123-9. [PubMed: 24250580].

7. Kalantari H, Jalali M, Jalali A, Mahdavinia M, Salimi A, Juhasz B, et al. Protective effect of Cassia fistula fruit extract against bromobenzeneinduced liver injury in mice. Hum Exp Toxicol. 2011;30(8):1039-44. doi 10.1177/0960327110386256. [PubMed: 20930029].

8. Moosavi M, Rezaei M, Kalantari H, Behfar A, Varnaseri G. Icarnitine protects rat hepatocytes from oxidative stress induced by T-2 toxin. Drug Chem Toxicol. 2016;39(4):445-50. doi: 10.3109/01480545.2016.1141423. [PubMed: 26888052].

9. Akhtar S, Ismail T, Fraternale D, Sestili P. Pomegranate peel and pee extracts: chemistry and food features. Food Chem. 2015;174:417-25. doi: 10.1016/j.foodchem.2014.11.035. [PubMed: 25529700].

10. Nuncio-Jauregui N, Munera-Picazo S, Calín-Sanchez Á, Wojdyło A, Hernandez F, Carbonell-Barrachina AA. Bioactive compound composition of pomegranate fruits removed during thinning.J Food Composit Analysis. 2015;37:11-9. doi:10.1016/j.jfca.2014.06.015.

11. Waly MI, Ali A, Guizani N, Al-Rawahi AS, Farooq SA, Rahman MS Pomegranate (Punica granatum) peel extract efficacy as a dietary antioxidant against azoxymethane-induced colon cancer in rat. Asian Pac J Cancer Prev. 2012;13(8):4051-5. [PubMed: 23098515].

12. Zeinalabedini M, Derazmahalleh MM, RoodbarShojaie T, Irandoost HP, Zahravi M, Vazifehshenas M, et al. Extensive genetic diversity in Iranian pomegranate (Punica granatum L.) germplasm revealed by microsatellite markers. Scientia Horticulturae. 2012;146:104-14.

13. Naziri Z, Rajaian H, Firouzi R. Antibacterial effects of Iranian native sour and sweet pomegranate (Punica granatum) peel extracts against various pathogenic bacteria. Iran J Vet Res. 2012;13(4):282-8.

14. Basiri S. Evaluation of antioxidant and antiradical properties of Pomegranate (Punica granatum L.) seed and defatted seed extracts. J Food Sci Technol. 2015;52(2):1117-23. doi: 10.1007/s13197-013-1102-Z. [PubMed: 25694727].

15. Al-Olayan EM, El-Khadragy MF, Metwally DM, Abdel Moneim AE. Protective effects of pomegranate (Punica granatum) juice on testes against carbon tetrachloride intoxication in rats. BMC Complement Altern Med. 2014;14:164. doi: 10.1186/1472-6882-14-164. [PubMed: 24884677].

16. Jiang D, Wu D, Zhang Y, Xu B, Sun X, Li Z. Protective effects of hydrogen rich saline solution on experimental testicular ischemia-reperfusion injury in rats. J Urol. 2012;187(6):2249-53. doi: 10.1016/j.juro.2012.01.029. [PubMed: 22503049].

17. Delazar A, Biglari F, Esnaashari S, Nazemiyeh H, Talebpour AH, Nahar L, et al. GC-MS analysis of the essential oils, and the isolation of phenylpropanoid derivatives from the aerial parts of Pimpinella aurea. Phytochemistry. 2006;67(19):2176-81. doi: 10.1016/j.phytochem.2006.06.012. [PubMed: 16857219].

18. Gharib FA, da Silva JAT. Composition, total phenolic content and antioxidant activity of the essential oil of four Lamiaceae herbs. Med Aromat Plant Sci Biotechnol. 2013;7(1):19-27.

19. Vador N, Vador B, Hole R. Simple spectrophotometric methods for standardizing ayurvedic formulation. Indian J Pharm Sci. 2012;74(2):161-3. doi: 10.4103/0250-474X.103852. [PubMed: 23325998].

20. Saad H, Charrier-El Bouhtoury F, Pizzi A, Rode K, Charrier B, Ayed $\mathrm{N}$. Characterization of pomegranate peels tannin extractives. Indust Crops Prod. 2012;40:239-46. doi: 10.1016/j.indcrop.2012.02.038.

21. Pande G, Akoh CC. Antioxidant capacity and lipid characterization of six Georgia-grown pomegranate cultivars. J Agric Food Chem. 2009;57(20):9427-36. doi: 10.1021/jf901880p. [PubMed: 19743855].

22. Negi PS, Jayaprakasha GK. Antioxidant and antibacterial activities of Punica granatum peel extracts. J Food Sci. 2003;68(4):1473-7.

23. Caetano NN, Campello AP, Carnieri EG, Kluppel ML, Oliveira MB. Effect of methotrexate (MTX) on NAD(P)+ dehydrogenases of HeLa 
cells: malic enzyme, 2-oxoglutarate and isocitrate dehydrogenases. Cell Biochem Funct. 1997;15(4):259-64. doi: 10.1002/(SICI)10990844(199712)15:4<259::AID-CBF749>3.0.CO;2-D. [PubMed: 9415972].

24. Babiak RM, Campello AP, Carnieri EG, Oliveira MB. Methotrexate: pentose cycle and oxidative stress. Cell Biochem Funct. 1998;16(4):283-93. doi: 10.1002/(SICI)1099-0844(1998120)16:4<283::AID-CBF801>3.0.CO;2E. [PubMed: 9857491].

25. Ali N, Rashid S, Nafees S, Hasan SK, Sultana S. Beneficial effects of Chrysin against Methotrexate-induced hepatotoxicity via attenuation of oxidative stress and apoptosis. Mol Cell Biochem. 2014;385(12):215-23. doi: 10.1007/s11010-013-1830-4. [PubMed: 24154663].

26. Yin LL, Zhang Y, Guo DM, An K, Yin MS, Cui X. Effects of zinc on interleukins and antioxidant enzyme values in psoriasis-induced mice. Biol Trace Elem Res. 2013;155(3):411-5. doi: 10.1007/s12011-013-9799-0. [PubMed: 24018880].

27. Vardi N, Parlakpinar H, Cetin A, Erdogan A, Cetin Ozturk I. Protective effect of beta-carotene on methotrexate-induced oxidative liver damage. Toxicol Pathol. 2010;38(4):592-7. doi: 10.1177/0192623310367806. [PubMed: 20448084].

28. Oktar S, Gokce A, Aydin M, Davarci M, Meydan S, Ozturk OH, et al. Beneficial effect of erdosteine on methotrexate-induced testicular toxicity in mice. Toxicol Ind Health. 2010;26(7):433-8. doi: 10.1177/0748233710369666. [PubMed: 20504824].
29. Hadi NR, Al-Amran FG, Swadi A. Metformin ameliorates methotrexate-induced hepatotoxicity. J Pharmacol Pharmacother 2012;3(3):248-53. doi: 10.4103/0976-500X.99426. [PubMed: 23129960].

30. Dalaklioglu S, Genc GE, Aksoy NH, Akcit F, Gumuslu S. Resveratrol ameliorates methotrexate-induced hepatotoxicity in rats via inhibition of lipid peroxidation. Hum Exp Toxicol. 2013;32(6):662-71. doi: 10.1177/0960327112468178. [PubMed: 23424212].

31. Toklu HZ, Dumlu MU, Sehirli O, Ercan F, Gedik N, Gokmen V, et al. Pomegranate peel extract prevents liver fibrosis in biliary-obstructed rats. J Pharm Pharmacol. 2007;59(9):1287-95. [PubMed: 17939210].

32. Wang JY, Zhu C, Qian TW, Guo H, Wang DD, Zhang F, et al. Extracts of black bean peel and pomegranate peel ameliorate oxidative stressinduced hyperglycemia in mice. Exp Ther Med. 2015;9(1):43-8. doi: 10.3892/etm.2014.2040. [PubMed: 25452774].

33. Kumar D, Singh S, Singh AK, Rizvi SI. Pomegranate (Punica granatum) peel extract provides protection against mercuric chloride-induced oxidative stress in Wistar strain rats. Pharm Biol. 2013;51(4):441-6. doi: 10.3109/13880209.2012.738333. [PubMed: 23336580].

34. Abdel Moneim AE. Evaluating the potential role of pomegranate peel in aluminum-induced oxidative stress and histopathological alterations in brain of female rats. Biol Trace Elem Res. 2012;150(1-3):328-36. doi: 10.1007/s12011-012-9498-2. [PubMed: 22945624]. 